\title{
NEOGENE SPECIATION IN (ONE OR TWO?) SMALL OCEANS
}

FORTUNATO*, Helena, Smithsonian Tropical Research Institute, Box 2072 Balboa, Panama; JACKSON, Jeremy B. C., Smithsonian Tropical Research Institute. Box 2072 Balboa, Panama.

Extrinsic geographic barriers are the most obvious mechanism for the isolation of marine populations and the origin of species. Such barriers are rare, however, and there is increasing biogeographic and genetic evidence that other mechanisms of isolation more commonly lead to speciation within continuous ocean basins.

The late Neogene formation of the Isthmus of Panama provides an excellent opportunity to compare the proportion of speciation events that occurred within a single ocean or across a developing land barrier, based on cladistic analysis of well preserved fossil lineages. The tropical American Genus Strombina contains 42 Caribbean and Eastern Pacific species ranging from the Early Miocene to recent. We used 50 shell characters to construct cladistic phylogenies to infer speciation events using Hennig86. Trees were rooted to either the most closely related Miocene outgroup (Sincola) or the oldest fossil species of the clade Strombina aldrichi, with similar results.

Analysis of the entire fauna revealed two distinct lineages of Strombina, but the phylogenetic position of many species in both of these clades was highly inconsistent with their stratigraphic position, suggesting extensive morphological convergence. To test for this we excluded all species that first appear in the Pleistocene or recent, as if we were paleontologists working at the end of the Pliocene. The resulting cladograms preserved the two main lineages but eliminated most of the stratigraphic inconsistencies, which were further reduced in analyses of exclusively Miocene species. We then worked back up the column, adding younger species within only a single lineage at a time, to produce a composite tree of relatively high stratigraphic and cladistic consistency.

The results show that the Isthmus was indeed an important geographic barrier that was breached only 4 or 5 times during the entire evolutionary history of Strombina. The S. (Strombina) clade colonized the Pacific in the Middle or early Late Miocene, with no subsequent mixing of the Caribbean and Pacific lineages. Likewise, each of the two principal branches of the second clade [S. (Lirastrombina) and S. (Spiralta)] colonized the Pacific only once during the Pliocene; after which the Caribbean and Pacific lineages remained distinct except for the recolonization of the Caribbean by a single species. Approximately $90 \%$ of the inferred speciation events occurred within a single ocean over distances less than $500-1000 \mathrm{~km}$. The isthmian barrier was of major importance to the establishment of new lineages but of trivial importance for speciation. 